\title{
Talking about animal research
}

\author{
Scientists and their institutions need to communicate more proactively to counter claims of \\ mistreatment by animal rights activists
}

\author{
Katrin Weigmann
}

I n June 2015, the extremist group Animal Liberation Front (ALF) destroyed two trucks belonging to Harlan Laboratories in Ontario, Canada. In the same month, Nikos Logothetis, a renowned neuroscientist at the Max Planck Institute for Biological Cybernetics in Tübingen, Germany, announced that he would abandon his research on nonhuman primates after months of harassment and slander from animal rights activists. In May 2014 and April 2013, animal rights activists forced their way into the Pharmacology Department of the University of Milan, Italy. They spread paint, broke glass, and removed information tags from animal cages, destroying years of work. In April 2014, the Tierversuchsgegner Bundesrepublik Deutschland placed a full-page advertisement in a number of Germany's national and regional newspapers, accusing neuroscientist Andreas Kreiter at the University of Bremen of "torturing" nonhuman primates in "pseudoscientific” experiments.

“

"... reluctance to speak up

leads to a paucity of

information about the use of

animals in research, which

benefits animal rights

activists."

Most scientists are fortunate that they do not become the target of such attacks. Nonetheless, all scientists who work with animals are indirectly affected by animal rights activism, because activists strike at random and spread fear. "Even if they don't target you directly, they have an incredible impact on the attitude of scientists. They spread reluctance among people to engage in a public debate," said David Jentsch, a behavioral neuroscientist at the University of California, Los Angeles, (UCLA), who has been personally attacked and is now fighting back.

$\square$ owever, this reluctance to speak up leads to a paucity of information about the use of animals in research, which benefits animal rights activists. "We delivered an informational void to the public and then stepped aside to allow fanatics to fill it with all kinds of fiction," said Cindy Buckmaster, Director of the Center for Comparative Medicine at Baylor College of Medicine in the USA and Chair of Americans for Medical Progress, a charity that promotes public understanding of the use of animals in biomedical research. Animal rights groups fill this information void with their side of the story along with misinformation about the use and fate of animals in biomedical research. The debate is strongly polarized, making it difficult for scientists to put forward a more nuanced view. Speaking up, some might think, is futile, or they might fear that they will draw themselves to the attention of activists. But if scientists ever want to escape the vicious circle of misinformation and fear, they need to tell the public their side of the story. "This philosophy of sticking our heads in the sand is fatal because it nourishes the myth of the animal rights activists that scientists have something to hide," said Christina Beck, Head of the Press and Public Relations Office of the Max Planck Society in Munich, Germany.

Hiding may not help anyway. "There are plenty of ways for activists to find out where animal research is done. In the end, advertising the position of an animal caretaker can be enough," Beck explained. This is how the
German activist group SOKO Tierschutz infiltrated the Max Planck Institute in Tübingen in September last year, determined to produce video material that could be used to demonstrate cruelty against animals. The German broadcast magazine Stern TV made the footage public in a highly manipulative context intended to stir up emotion. SOKO Tierschutz organized a demonstration in Tübingen, which attracted up to 1,200 participants, while researchers and their families received hate mail and were harassed and threatened. Nikos Logothetis, Director at the institute, eventually announced that he would stop working with primates. Although Christina Beck is located in Munich, where the Max Planck Society has its administrative offices, she took over the communication lead at the Tübingen Institute, which did not have a press officer at that time.

c6

... if scientists ever want to escape the vicious circle of misinformation and fear, they need to tell the public their side of the story."

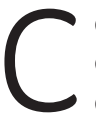
ommunication during a crisis is extremely difficult and follows its own rules that are distinct from common practice in science. "There is no room to explain things at length; you have to resort to simple and clear claims. You have to be aware that your opponent is operating on a very emotional level," Beck said. Images in particular have a strong impact on emotions. Monkeys behind bars, or, as in the Tübingen footage, rare pictures of a severely ill monkey after surgery, are 


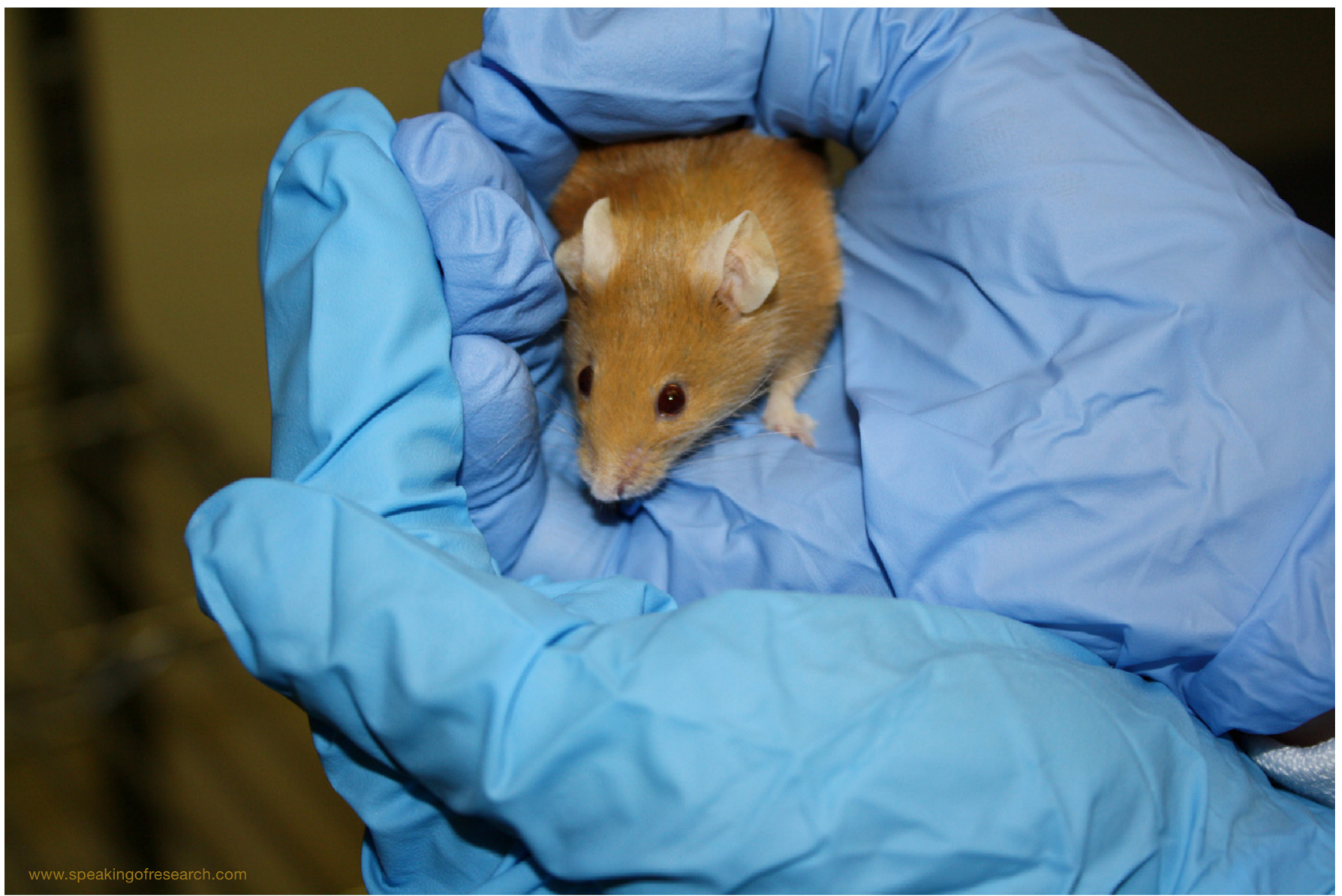

challenging and hard to argue against. "In a crisis, you cannot answer with rational explanations. People do not ask about your research - all they are interested in is: 'Why do we see these pictures'," she explained. "The only way to regain credibility is by calling on an independent commission to investigate all allegations."

There is no guaranteed way to avoid becoming a target of animal rights extremists, but institutions and researchers can minimize the impact of such harassment. Because explaining research and providing neutral information are nearly impossible when emotions run high, it is all the more important to do so in advance. "You are in a better position in a crisis situation when you have communicated transparently beforehand," Beck explained. If the local population is well informed about the research, activists will be less likely to incite them against researchers. "Radical activists will always be there - there is not much we can do about that," Beck said. "But what we can do is to provide the public with factually well-founded information and find supporters among them. We need to impact on the broader public to not leave the field to the activists."

E ver since he took a faculty position at UCLA in 2001, animal rights activism has been a constant companion for David Jentsch. The university had long been targeted by an active group of animal rights extremists, the Animal Liberation Front, but by 2006, their "activism" had become increasingly violent, including arson, home flooding, and razor blades in the mail. "It had a major impact on the entire university community. People were worried about who was the next person to be targeted," Jentsch said. In 2009, he became a direct victim of their actions, when they set his car on fire right in front of his house. "At that point I had a cathartic moment where I was going to either fall victim to their actions or turn that aggression into an affirmative response of my own part," he said. He decided for the latter: "It was not an easy decision." What helped him find the courage was the consideration that the violence was not aimed at him personally. "It was a message to scientists everywhere that you could be next. I realized that this was much bigger than one person and we needed a more community-based response," he said. In addition, support from his colleagues gave him courage: "Most of the cases where people have not been able to [continue their work], they did not have this internal support."

Shortly after his car was burned, Jentsch founded UCLA Pro-Test (now Pro-Test for Science), named after Pro-Test, a UK-based group that successfully defended the construction of a large animal research facility at Oxford University in 2006. Jentsch organizes rallies to stand up to extremism, and he campaigns to promote humane and responsible animal research through science media, public media, blogs, and twitter. In addition, he travels to scientific conferences and gives talks to encourage more scientists to become engaged. Some of his more invisible efforts include being a resource for other scientists who have been targeted. "I will do anything to aid them, and sometimes I can give tips and insights that were helpful for 
us in our university to deal with the problem," Jentsch said.

\section{"Because explaining research} and providing neutral information is nearly impossible when emotions run high, it is all the more important to do so in advance."

Florian Dehmelt is another researcher who speaks up. He has not been targeted himself, but he followed closely the events around Nikos Logothetis from abroad, as he was planning to return to Germany to start a postdoctoral research project at the University of Tübingen. "I was appalled to see how such an important debate was conducted in my home country - that a small radical minority has managed to drive Dr. Logothetis out of research through harassment and slander," he said. A number of people felt the same and the office grapevine brought them together. "Many of us thought: 'This is enough. I cannot justify remaining silent to myself anymore'," Dehmelt said. Then, a group of about 20 scientists, some of whom work with animals and some not, founded Pro-Test Germany.

Of course, they were anxious in the beginning. Dehmelt recalled the first few meetings: "It was a room full of people who feared nothing more than their names or pictures going public." But the group grew with their task. They issued a press release and started a website with information about animal research-which now includes the names and pictures of many group members. They distributed flyers on the marketplace in Tübingen, and Dehmelt -as the "face" of the group-gained his first media experience and was featured on radio and TV. Their message has already reached a large number of people, but there is another aspect in which they have succeeded: "Self-therapy has already kicked in. Our fear is gone," Dehmelt commented.

"Our goal is not to blindly advertise animal research - I would find that inappropriate-but to explain how it is done and why," he explained. "It is about creating a climate of open discourse [...] Animal research is, in the end, a moral decision, and different people will reach different conclusions. We, as researchers, are not morally superior. However, we do have some information and firsthand experience that we would like to share," he said.

A lthough the majority of animals used in research do not suffer, some do. This fact should not be denied, but rather acknowledged and discussed. It is important to explain that animal research is done for a reason and that without such research, medical progress would halt or slow down. "Animal research is not always, but it can be harmful to the animal. And because of that, it has to be justified," Jentsch said.

Most people who take medicine are not necessarily aware that its development involved animal research. They read newspapers and come across articles that mention research using "animal models," but they do not think about what that means and that there is a connection between the two. People have been allowed what Cindy Buckmaster calls the "luxury of the disconnect": "Every day they experience another miracle. But they want to pretend they come from nowhere. They don't want any accountability for what it takes for them to have these miracles," Buckmaster explained. Moreover, most people know little about the relevance of basic research: "They think that animal research starts and ends with safety and efficacy tests that happen before drugs are tested in clinical trials. It does not occur to them that basic research is required to understand the molecular and cellular basis of health and diseases," she said. Animal rights activists exploit this ignorance when spreading the myth that "most animal experiments are not relevant to human health" and "many are undertaken simply out of curiosity" (http://www.peta. org/issues/animals-used-for-experimentation/ animal-testing-bad-science/). With such claims, they provide an easy way out: Take the medicine and blame researchers for harming the animals.

Researchers thus need to talk about the importance of animal research, including addressing difficult questions: How do animals die? What is a "mouse model of cancer"? Do the animals feel pain in certain procedures? To Dehmelt, complete transparency is the only solution: "Where do people go if they want to know how monkeys are put down?" he asks. It would be helpful for them to receive such answers from scientists rather than the views put forward by animal rights activists.

$\mathrm{T}$ here are many possible ways to engage in communication, Jentsch explained: "You need to play to people's comfort zones and their talents." He distinguishes different spheres in which people can get involved. One is communicating with the lay public about why science is done, how it is conducted, and how scientists ensure it is done responsibly. Within this area, there is what he calls "controlled messaging”- - tweeting, facebook, bloggingwhere scientists have the opportunity to craft a message and get it to as many people as possible. The other part is "uncontrolled messaging" where a scientist talks with somebody and answers questions. "Not everybody feels comfortable in engaging in uncontrolled messaging, but I think it is absolutely critical to the community. Public trust in those kinds of messages is greater because they feel you subjected yourself to the really hard questions," Jentsch said. In addition, it shows scientists as human beings, which is essential when others are portraying them as villains.

\section{"It is important to explain that animal research is done for a reason and that without such research, medical progress would halt or slow down."}

Another area is promoting communication within the scientific community. “There are things in science we don't talk about with each other. Euthanizing animals, for example, is an emotional and psychologically challenging thing to do," Jentsch said. As long as scientists do not talk to their peers about these aspects of research, how will they manage to do so in public?

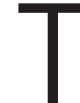

alking to the public about animal research can be challenging, but press offices of research institutes and universities should be able to help. In addition, there are a number of institutions and organizations that provide guidance and make resources available on their websites. For example, the Science Media Center advises scientists who are experiencing 
harassment and has guideline for talking to the media about animal research (http:// www.sciencemediacentre.org/publications/ publications-for-scientists/). Speaking of research in the USA (http://speakingof research.com/), as well as Understanding animal research in the UK (http://www. understandinganimalresearch.org.uk/), provides comprehensive information about animal research for the broader public that can also be informative for scientists interested in public communication. Both sites also include a long list about the typical myths and misconceptions on animal research.

\section{"Researchers thus need to talk about the importance of animal research, including addressing difficult questions ..."}

According to Buckmaster, using the right language is crucial when talking about animal research. "We love animals, we treat them with compassion and respect," she said. This is an important message for scientists to convey because animal rights activists usually paint a very different picture. Compassion and respect should also be reflected in the language scientists use to talk about their work: "Do not say that you 'use' animals for your research, or that research is 'done on' them. Tell people you 'work with' animals,” Buckmaster suggested. In addition, she warns about using the word "experiment". "Researchers say it all the time, but it can mean something very different to the public," she explained, "something far from the well-considered, hypothesis-driven studies that we do." The word "exploits the representation of poorly conceived, mad science that popular horror movies and books have etched in our minds," Buckmaster wrote in an article about communicating animal research [1].

\section{"When scientists open their laboratories and let the public visit animal facilities, they may need some support."}

Depending on the situation, scientists may also be confronted with emotional reactions from opponents or insulting allegations. "Don't let anyone provoke you to shout back-stay calm," Dehmelt recommended. He has some suggestions on how to proceed: "If someone comes up with a general assertion that is only supposed to make you look bad, counter with a very concrete question-not to distract, but to make them focus again on what they really mean, moving away from insults and toward a tough, but helpful conversation. When someone says: 'You are a sadistic murderer', answer by asking: 'Why do you think so?'” Dehmelt explained that a similar strategy can be applied to rhetorical questions as follows: "How can you do that?", "Don't you have nightmares?" or "Don't you care if the animals suffer?" "You can readily accept these as genuine questions and give honest answers," he said. "If you do so, that really helps to better understand each other."

When scientists open their laboratories and let the public visit animal facilities, they may need some support. Beck suggested that scientists should ask their institutional press offices for help and training. Beck said that although it is rare that activists try to disturb an event, "scientists feel more safe if they are prepared."

he quantity and aggressiveness of animal rights activism varies by country. In Germany, violent activism has been rather rare, but the UK has a long history of such events, which has given the country's scientists and law enforcement agencies a head start in fighting back [2]. Pro-Test Deutschland, Pro-Test Italia, and Pro-Test for Science (USA) were all built on the model of the organization Pro-Test, which formed in 2006 in the UK and successfully defended the construction of an animal research facility at Oxford University. Since then, many institutions in the UK have realized that open communication is a good strategy to gain public support for animal research, and animal rights extremism has dropped. In May 2014, the Concordat on Openness in Animal Research in the UK was launched (see http://www.understandinganimalresearch.org.uk/policy/concordat-openness-animal-research/), which "commits its signatories to supporting clear, transparent and open communication and proactive public engagement on this subject." Ninetyone institutions in the UK have signed up and will now follow a common approach to the challenge of "providing the public with better insights into the reasons for, methods of, and progress resulting from, the use of animals in research." Beck applauds this effort and hopes for something similar in Germany. "We need to reach the population at large, and this can only be achieved through a joint action," she said. Jentsch takes a similar view: "Scientific advocacy is the responsibility of the entire community, and it can only really be successful if it happens at that level."

\section{References}

1. Buckmaster C (2013). You're HeroesShare Your Truth! Laboratory Animal Science Professional June 2013: 15-18

2. Holder T (2014) Standing up for science: the antivivisection movement and how to stand up to it. EMBO Rep 15: $625-630$ 